\title{
Interseções entre socialização de gênero e violência contra a mulher por parceiro íntimo
}

\author{
Intersections between gender socialization \\ and violence against women by the intimate partner
}

Dinair Ferreira Machado (https://orcid.org/0000-0003-3006-7110) ${ }^{1}$

Elen Rose Lodeiro Castanheira (https://orcid.org/0000-0002-4587-7573) ${ }^{1}$

Margareth Aparecida Santini de Almeida (https://orcid.org/0000-0002-4603-2513) ${ }^{1}$

${ }^{1}$ Faculdade de Medicina - Campus Botocatu, Universidade Estadua Paulista Julio de Mesquita Filho. Av. Prof. Mário Rubens Guimarães Montenegro s/n. 18618687 Botucatu SP Brasil. dinair.machado@unesp.br

\begin{abstract}
The scope of this article is to identify intersections between gender socialization and intimate partner violence against women. It involves qualitative research in the mold of the topical life story. The study included 16 women who filed a police report in a Police Station for the Defense of Women in a city in the interior of São Paulo. For the interviews a semi-structured script that examined women from their childhood memories, family dynamics, relationship/marriage and post-marriage/marriage family dynamics was used. The patriarchal system as a societal order underpinned the socialization of these women who, because of the father's domination relations (patriarchy) and guided by the mother's model of submission, sought freedom in marriage/early unions with partners who repeated paternal behavior. Such family contexts may have influenced them in choosing potential aggressors. The results revealed that gender socialization reinforces gender inequalities and influences the behavior of men and women, thus pointing out the importance of highlighting this problem in different areas, especially in primary health care services, as a way to prevent intimate partner violence against women. Key words Gender socialization, Violence against women, Domestic violence
\end{abstract}

Resumo O objetivo deste artigo é identificar interseções entre socialização de gênero e violência contra a mulher por parceiro intimo. Trata-se de pesquisa qualitativa nos moldes da história de vida tópica. Participaram do estudo 16 mulheres que lavraram B.O em uma Delegacia de Defesa da Mulher de um município do interior paulista. Para as entrevistas, foi utilizado um roteiro semiestruturado que abordou as mulheres a partir de suas lembranças da infância, da dinâmica familiar, da união/casamento e da dinâmica familiar pós-união/casamento. O patriarcado enquanto ordem societária orientou a socialização dessas mulheres, que, por causa das relações de dominação do pai (patriarca) e orientadas pelo modelo de submissão das mães, buscaram liberdade em casamento/uniões precoces com companheiros que reproduziram o comportamento paterno. Tais contextos familiares podem tê-las influenciado na escolha de potenciais agressores. Os resultados demonstraram que a socialização de gênero reforça desigualdades entre os sexos e norteia os comportamentos de homens e mulheres, apontando assim para a importância de se problematizar esse tema em diferentes espaços, especialmente nos serviços de atenção primária à saúde, como forma de prevenir relações de violência contra a mulher por parceiro intimo.

Palavras-chave Socialização de gênero, Violência contra a mulher, Violência doméstica 


\section{Introdução}

A violência contra a mulher por parceiro íntimo é um grave problema de saúde pública, e que pode ser prevenido quando abordado sob a ótica das relações sociais de gênero. De acordo com mapa da violência de 2015, dos 4.762 assassinatos de mulheres notificados em 2013, 50,3\% ocorreram por familiares, sendo $33,2 \%$ cometidos por seus parceiros íntimos. A cada sete assassinatos de mulheres, quatro foram feminicídios ${ }^{1}$.

No ano de 2013, o país apresentou taxa de 4,8 assassinatos em cada 100 mil mulheres, o que piorou sua posição no ranking dos países com maior índice de feminicídio. Desse modo, o Brasil passou a ser o quinto país que mais mata mulheres, ficando atrás de El Salvador, Colômbia, Guatemala e a Federação Russa ${ }^{1}$.

Esses dados alarmantes demonstram o desfecho de um problema complexo que requer uma compreensão ampliada sobre o fenômeno da violência contra a mulher sob a perspectiva cultural e histórica da construção social de gênero, sendo essa uma forma de enfrentar e prevenir tais resultados ${ }^{2-4}$. Essa perspectiva converge em direção as questões colocadas para a saúde coletiva, em especial na interface entre a perspectiva da saúde integral e a conquista de direitos humanos e sociais, o que requer abordagens interdisciplinares relativas às questões de gênero ${ }^{5}$.

$O$ conceito de gênero, alicerçado no termo relações de gênero, corresponde à ideia de que o masculino e o feminino extrapolam o sexo biológico. Compreende construções sociais a respeito de: quais são os papéis adequados aos homens e às mulheres na sociedade; origens sociais de suas identidades e subjetividades; e como se estruturam em uma relação de poder ${ }^{6}$. Configura-se enquanto uma gramática sexual em que não apenas as relações homens e mulheres são reguladas, mas também as relações entre homem-homem e mulher-mulher ${ }^{7,8}$.

A construção social de gênero se faz também por meio da representação em diferentes instâncias, discursos e práticas da vida cotidiana e instituticionalizadas, como as de sáude ${ }^{9}$. A essência do conceito de gênero está nas diferenças construídas culturalmente em torno do que se espera do homem, visto como um ser superior, e da mulher como um ser inferior, resultado de uma sociedade patriarcal em que ao homem foi destinado o poder de dominação, e à mulher, a submissão $0^{10-12}$.

As relações de gênero inserem o indivíduo no mundo e influenciam suas trajetórias, escolhas, vivências e oportunidades ${ }^{13,14}$. Encontram-se pre- sente no processo de socialização dos indivíduos ao definirem: valores e normas socioculturais, $\mathrm{o}$ modo como homens e mulheres devem se portar na sociedade, e os papéis a serem exercidos em relação à divisão sexual do trabalho ${ }^{15,16}$. A condição da mulher representada pelo "sexo frágil", submissa e inferior ao homem, foi difundida de diferentes formas ao longo da história. Na contemporaneidade, essa ideia ainda permanece, apesar de avanços, em diferentes contextos e de diferentes maneiras ${ }^{10-12}$.

Assim como outros fenômenos sociais, o patriarcado também está em permanente processo de transformação. Nas palavras de Saffioti (p. 48): "Se, na Roma antiga, o patriarca detinha poder de vida e morte sobre sua esposa e seus filhos, hoje tal poder não mais existe no plano de jure" (p. 48) ${ }^{8}$. Porém o patriarcado se configura como tipo hierárquico de relação que ainda permeia a sociedade como um todo, uma ordem societária que favorece o controle masculino na sociedade, enaltecendo a superioridade do homem e a inferioridade da mulher.

As relações de poder e dominação própria do patriarcado estão presentes na forma com que os individuos são socializados, e desde o nascimento a socialização já está voltada para que assumam papéis e estereótipos próprios de cada sexo. Nesse sentido, a socialização de gênero é entendida como um processo que determina o que se espera de uma mulher e de um homem antes mesmo do nascimento. São regras sociais e expectativas reproduzidas por família, escola, igreja, entre outros, norteadas pelo sexo biológico ${ }^{17}$.

Nesse contexto, o presente artigo tem como objetivo identificar como se deu a influência da socialização do gênero na história de vida de mulheres em situação de violência por parceiro íntimo, à luz da análise do patriarcado.

\section{Método}

Trata-se de uma pesquisa qualitativa enquanto estratégia metodológica, que permite a compreensão dos fenômenos, dos processos e das atividades humanas, ao trabalhar com: valores, costumes, crenças, atitudes, hábitos e opiniões de um determinado grupo $^{18}$.

Este estudo é um recorte de uma pesquisa maior que investigou boletins de ocorrências registrados por 440 mulheres que formalizaram denúncia na Delegacia de Defesa da Mulher (DDM) de um município do interior paulista no período de abril de 2013 a março de 2014, 
das quais 150 relataram ter convivido por mais de cinco anos com o agressor. O recorte de cinco anos de convivência foi escolhido por ser um período em que a mulher pode vivenciar o ciclo da violência ${ }^{19}$ repetidamente sem romper com a união, podendo ter forte influência da socialização de gênero.

Desse universo de 150 mulheres, buscou-se entrevistar ao menos uma mulher dos seguintes grupos de características: faixas etárias $(19 \leq 29$; $30 \leq 39 ; 40 \leq 49 ; 50 \mathrm{e}+$ ) e níveis de escolaridade ( $1^{\circ}$ grau completo; $2^{\circ}$ grau completo; técnico; superior incompleto; e superior completo), garantindo-se assim vivências em diferentes contextos e situações (Quadro 1).

Ao final, foram contatadas e convidadas 54 mulheres para entrevistas, das quais 15 não aceitaram participar logo no primeiro contato, 13 no segundo contato e 10 não compareceram para a entrevista mesmo remarcando duas vezes.

Por fim foram incluídas 16 mulheres no estudo, que foram entrevistadas nos moldes da história de vida tópica, modalidade que possibilita enfatizar determinadas experiências das trajetórias de vida dos entrevistados ${ }^{18}$. Para as entrevistas, foi utilizado um roteiro semiestruturado que abordou as mulheres a partir de suas lembranças da infância, da dinâmica familiar, da união/ casamento e da dinâmica familiar pós-união/casamento. Para a análise das entrevistas, optou-se pela análise de conteúdo de Bardin, na modalidade de análise temática ${ }^{20}$.

O convite para as entrevistas foi realizado mediante contato telefônico, a partir do Centro de Referência Especializado de Assistência Social (CREAS), o que facilitou a adesão à pesquisa, pois a maioria delas conhecia o serviço ou por ele foi atendida.

A pesquisa foi submetida e aprovada pelo Comitê de Ética da Faculdade de Medicina de Botucatu/UNESP.

Os nomes das mulheres deste estudo foram substituídos pelos de feministas brasileiras, em homenagem a toda luta e enfrentamento da opressão feminina nos diferentes contextos sociais e históricos. Das mulheres homenageadas, apenas Maria da Penha está fisicamente entre nós, as demais vivem em nossos ideários de luta pelo fim da desigualdade de gênero. Em especial Marielle, que teve sua voz calada em 14 de março de 2018.

Quadro 1. Distribuição das mulheres segundo idade, escolaridade, ocupação e renda.

\begin{tabular}{|l|c|l|l|c|}
\hline \multicolumn{1}{|c|}{ Nome } & Idade & \multicolumn{1}{|c|}{ Escolaridade } & \multicolumn{1}{c|}{ Ocupação } & $\begin{array}{c}\text { Renda } \\
\text { familiar (R\$) }\end{array}$ \\
\hline 1. Maria Quitéria de Jesus & 64 & Fundamental I completo & $\begin{array}{l}\text { Aposentada } \\
\text { serviços gerais }\end{array}$ & $1.700,00$ \\
\hline 2. Nísia Floresta Augusta & 56 & Fundamental I completo & $\begin{array}{l}\text { Aposentada } \\
\text { serviços gerais }\end{array}$ & 880,00 \\
\hline 3. Chiquinha Gonzaga & 55 & Superior completo & Dentista & $20.000,00$ \\
\hline 4. Maria da Penha & 55 & Médio incompleto & Escriturária & $1.500,00$ \\
\hline 5. Maria Firmina dos Reis & 47 & Fundamental I incompleto & Diarista & 800,00 \\
\hline 6. Anita Garibaldi & 43 & Médio completo & Desempregada & $6.000,00$ \\
\hline 7. Maria Lacerda de Moura & 42 & Médio completo & Frentista & $2.500,00$ \\
\hline $\begin{array}{l}\text { 8. Hipólita Jacinta Teixeira de } \\
\text { Mello }\end{array}$ & 41 & Médio completo & $\begin{array}{l}\text { Auxiliar serviços } \\
\text { gerais }\end{array}$ & 950,00 \\
\hline 9. Bárbara Alencar & 41 & Fundamental II completo & Desempregada & $1.200,00$ \\
\hline 10. Bertha Lutz & 35 & Médio completo & Auxílio doença & $1.500,00$ \\
\hline 11. Laudelina de C. Melo & 35 & Superior incompleto & Analista fiscal & $3.000,00$ \\
\hline 12. Rose Marie Muraro & 32 & Mestrado em andamento & Bolsista CAPES & $2.000,00$ \\
\hline 13. Patrícia Galvão (Pagu) & 31 & Médio completo & Diarista & $1.200,00$ \\
\hline 14. Marielle Franco & 31 & Fundamental II em andamento & Do lar & $1.600,00$ \\
\hline 15. Maria Amélia de Queiroz & 31 & Médio incompleto & $\begin{array}{l}\text { Empregada } \\
\text { doméstica }\end{array}$ & 900,00 \\
\hline 16. Leonilda Daltro & 25 & Fundamental II incompleto & Desempregada & Sem renda \\
\hline
\end{tabular}

* O ensino fundamental I vai do $1^{\circ}$ ao $5^{\circ}$ ano de estudo. O fundamental II vai do $6^{\circ}$ ao $9^{\circ}$ ano. O ensino médio corresponde a 12 anos de estudo. 


\section{Resultados}

A idade média das mulheres foi de 44,06 anos. Seis tinham até o fundamental completo, sete até o ensino médio completo, e outras três superior incompleto, superior concluído ou mestrado acadêmico em curso.

Em relação à ocupação, com exceção de uma que exercia apenas atividade no lar e duas desempregadas, todas exerciam atividade remunerada. As ocupações eram compatíveis com o nível de escolaridade atingido, ou seja, as mulheres com no máximo fundamental completo exerciam atividades como diaristas e empregadas domésticas; as com até ensino médio, serviços gerais. Das três que tinham o ensino superior completo e incompleto, uma era odontóloga, outra era analista fiscal e uma estava cursando mestrado acadêmico e recebia bolsa de estudos.

A média de renda familiar das participantes foi de $\mathrm{R} \$ 2.858,12$ quando considerada no cálculo a renda de Chiquinha Gonzaga, de R\$ 20.000,00, que, por ter curso Superior, carreira consolidada e atuar na profissão de odontóloga com consultório próprio, tinha uma renda familiar que destoava das demais participantes, aumentando a média final. Quando retirada a renda dela, a média da familiar das participantes diminui para $\mathrm{R} \$ 1.715,33$.

A idade média das participantes é próxima à de mulheres que participaram de outros estudos brasileiros sobre violência contra a mulher, cuja faixa etária está entre 24 e 45 anos $^{21}$. A maior escolaridade encontrada diferencia-se de outros estudos, que indicaram mulheres em situação de violência com baixo nível de escolaridade, o que poderia levar a um maior grau de tolêrancia à situação de violência. Para as participantes, o fato de ter uma escolaridade maior, e até mesmo de a maioria estar inserida no mercado de trabalho, não significou romper mais cedo com o silêncio da violência. Esta, por ser um fenômeno sociocultural, atinge as mulheres de todas as camadas sociais, e a diferença está na oportunidade de acesso a diferentes recursos ${ }^{22}$. Após a análise das entrevistas foi possível identificar as seguintes categorias reveladoras da influência da socialização de gênero, pautada no patriarcado, para futuras situações de violência por parceiro íntimo: 1) reconhecendo a divisão sexual do trabalho na infância; 2) o patriarcado como norteador da busca por liberdade; 3 ) o casamento e a gravidez na adolescência como perspectiva de liberdade; e 4) reconhecendo o comportamento do pai no companheiro agressor.

\section{Reconhecendo a divisão sexual do trabalho na infância}

Essas mulheres vivenciaram a divisão sexual do trabalho desde a infância. Ao substituírem a mãe nas tarefas domésticas e assumirem os cuidados com os demais membros, especialmente os homens, essas mulheres foram sendo socializadas para o papel historicamente atribuído à mulher pela sociedade patriarcal. $O$ fato de ser mulher já pressupunha a ocupação do lugar das mães nessas tarefas. "Chegava em casa e tinha que fazer todo serviço da casa para minha mãe, não tive essas coisas de criança" (Hipólita).

A fala de Hipólita denuncia sua convicção de quem era a responsabilidade por tais tarefas e quem ela estava ajudando a realizar, a "mãe", o que indica claramente seu lugar na divisão sexual do trabalho, inclusive isentando os homens das atividades domésticas.

As mães das participantes desta pesquisa cobravam delas o exercício e a prática rigorosa de seus papéis, independentemente da idade. "A minha infância eu tive que amadurecer muito rápido, com seis anos minha mãe me ensinou a fazer arroz, fazer comida, desligar o fogão. Meus irmãos tinham três e quatro anos e eu tinha seis, eu subia na cadeira pra fazer as coisas, pra mexer no fogão" (Pagu).

Marielle teve a infância e a adolescência roubadas pelos trabalhos domésticos, sendo responsável pelo cuidado com a casa, os irmãos e a vigilância da avó. "Eu que cuidava dos meus irmãos por ser a mais velha. Era eu e meus irmãos, a minha vó só vinha dar uma olhadinha, mas trocar fralda e dar mamadeira era tudo eu que fazia, e na época tinha 12 anos" (Marielle).

\section{O patriarcado como norteador da busca por liberdade}

A posição paterna nas várias narrativas foi fundamentada pelo medo de que as filhas exercessem a sexualidade antes do casamento, o que justificaria o impedimento do contato com pessoas do sexo oposto, fossem amigos ou namorados. Tais modelos trazidos da cultura patriarcal passam a fazer sentido na mentalidade dessas mulheres, posteriormente norteando seus modos de pensar, agir e se comportar na sociedade. "Daí eu olhei assim e falei: 'Eu não posso namorar, meu pai não deixa'. Ele falou: 'Deixa, eu vou lá e converso com ele, você vai ser minha'” (Maria Quitéria).

Houve situações em que a mulher teve de escolher entre namorar ou estudar, pois sob a visão 
paterna não era possível conciliar as duas coisas. "Deu dois anos meu pai pediu pra eu largar dele. Só que eu estudava, e daí eu falei: 'Pai não posso largar de uma pessoa que eu gosto e não posso casar porque eu quero fazer curso, eu quero poder ter um futuro melhor. Meu pai disse não, então você largue dele já que você quer estudar, você larga dele” (Pagu).

Muitas vezes, as mulheres acabavam cedendo à dominação do pai: "Só que o meu pai me tratava como uma princesinha que ninguém podia mexer, a qual devia sempre obedecer, sem questionar, então não foi muito fácil” (Pagu). A superproteção do pai de Pagu, por si só, destaca a situação passiva esperada da filha, de quem não é capaz de se cuidar sem a proteção de um homem, na ocasião o pai, e futuramente o marido. "Meu pai me batia, às vezes por pouca coisa, eu sempre o respeitei, nunca falei mal ou reclamei porque eu tinha muito medo dele. Também não deixava usar saia, shorts, só perto do joelho. Minha adolescência foi muito difícil” (Pagu).

O mesmo pai que a tratava com zelo e proteção utilizava a violência e o medo para manter a autoridade e não ser contrariado pela filha, submetendo a seu crivo inclusive o tamanho e o tipo de roupa que a filha usava.

É interessante observar que os pais não permitiam outras formas de vivenciar a adolescência que não fosse a relacionada aos afazeres domésticos e cuidados dos irmãos. As filhas eram proibidas de estudar, passear e, sobretudo, namorar. "Eu ia com o meu pai numas festas, dessas da igreja, dai meu pai ficava bravo, falava para mim que não era para sair de perto dele e ficar no escurinho com os moleques" (Maria Lacerda).

A solução era namorar escondido, sem a orientação dos pais sobre as decisões e as escolhas a serem tomadas, sem a proteção a que teriam direito nessa fase da vida. Tais escolhas, quando reveladas, tornaram-se motivos de conflito e sofrimento na relação pai e filha. "Namoramos escondidos quase um ano. Depois ele quis me pedir em namoro para o meu pai, que não permitiu. Nossa! Chorei muito, meu pai era muito ruim, fiquei muito tempo sem falar com ele por isso. Namorei mais dois anos escondida e depois fugi de casa" (Bertha).

Maria Amélia não teve a figura paterna presente na socialização devido ao falecimento precoce. Porém, a mãe exerceu fielmente a cultura patriarcal sobre ela e as irmãs, que se recusaram a entrar de imediato em um relacionamento para fugir da opressão e foram morar sozinhas. "Minha irmã mais velha já tinha ido morar sozinha antes, eu e minha irmã do meio saímos também, porque a minha mãe ela era muito ruim, batia em nós. Ela era terrível, queria que casássemos logo. Como nós queríamos ter a nossa vida, saímos de casa, na época eu tinha 17 anos.”

\section{$O$ casamento e a gravidez na adolescência como perspectiva de liberdade}

Ao não enxergar alternativas para alterar o contexto familiar, ainda na adolescência Pagu saiu de casa para se livrar da opressão paterna, sendo a união precoce a forma utilizada para alcançar a tão sonhada liberdade e poder experimentar novas vivências. "Aos 17 anos saí fugida de casa, eu queria ter a minha liberdade" (Pagu).

A falta de liberdade e as agressões sofridas pelo pai não permitiam que as mulheres, ainda na adolescência, tivessem maturidade para fazer escolhas. Em geral, as decisões foram tomadas em um momento de desespero, como um grito de socorro, uma alforria, conforme relatou Pagu. "Aí começou a brigar (referindo-se ao pai), ele não deixava meu namorado entrar em casa, a gente namorava pra fora, foi um ano levando assim. [...] Até que um dia ele não aguentou e foi pra me bater (referindo-se ao pai), daí eu fui embora com meu namorado" (Pagu).

$\mathrm{Na}$ verdade, o que estas mulheres buscavam já na adolescência era a autonomia tanto para conquistar a liberdade quanto para poder viver saudavelmente sua vida nas diferentes dimensões: sexual, profissional e familiar. Entretanto, a falta de autonomia e a opressão da dinâmica familiar contribuíram para a tomada de decisões precipitadas, saindo de casa para morar com o namorado, e também dificultaram, no futuro, a escolha de terminar o relacionamento e sair da situação de violência.

Essa situação ficou evidente na fala de Hipólita, que conviveu com o companheiro agressor por 24 anos. "Conheci esse um aí, foi meu marido, morei com ele 24 anos."

A gravidez na adolescência e a união precoce foram a alternativa de fuga da relação opressora com o pai. "Eu comecei a namorar com 15 anos e com 17 já estava grávida e casada” (Laudelina).

No entanto, sair de casa não era a primeira opção, teve mulher que encontrou uma estratégia para conciliar os momentos de namoro e os estudos. "Eu arrumei um namoradinho com 13 anos, meu pai não deixava namorar em casa, então eu namorava nas esquinas e na frente da escola" (Hipólita). Porém, ainda assim ela não conseguiu manter a situação por muito tempo e 
acabou se casando e convivendo por 24 anos com o companheiro agressor.

Para outras, sem alternativas de enfrentamento da situação, a única opção foi sair de casa para se livrar da opressão paterna. O desejo de liberdade parecia tão distante que foi classificado como um sonho: "Eu queria sair da minha casa e conquistar minhas coisas, ter a minha casa, ter minha liberdade. Ah, sei lá, acho que eu era muito sonhadora" (Leonilda). O sonho de liberdade dela logo se desfez. "No começo ele era uma pessoa muito boa, mas quando eu engravidei, aos 17 anos, do meu primeiro filho, meu marido começou a se mostrar."

A vontade de ser livre levou as participantes a construírem uma família como forma de obter liberdade e autonomia: "Mais é a pressão também! A gente queria ter casa, filhos, liberdade, o marido" (Maria da Penha).

\section{Reconhecendo o comportamento do pai no companheiro agressor}

O impacto da socialização reforçada pela desigualdade de gênero contribuiu para que as mulheres, sem apoio familiar, liberdade e autonomia, consolidassem uniões com homens que reproduziram o comportamento paterno machista, com expectativas tradicionais sobre os papéis de gênero.

A decisão de sair de casa, de dar um ponto final nas agressões verbais, físicas e ter sua própria liberdade sem opressão, sem medo, foi fonte de arrependimento quando as participantes se deram conta de que o companheiro estava reproduzindo o mesmo comportamento do pai delas. Porém, para algumas a situação foi ainda mais complicada, pois já estavam grávidas ou o parceiro não aceitava o fim do relacionamento.

Pagu saiu de casa em busca de liberdade, fugia do comportamento controlador e possessivo do pai, porém se mostra frustrada quando reconhece o mesmo comportamento no companheiro. "E eu pensava que ele iria gostar de sair, só que a gente casou e não foi isso que aconteceu, e foi a primeira decepção" (Pagu).

Quando observa que o padrão de comportamento do parceiro não era diferente do que vivenciou em casa com o pai, Laudelina se arrepende e reconhece ter feito a escolha errada. "Depois de um ano de casados ele começou a se mostrar a pessoa que ele era pra mim, ele não era mais aquele homem tão bom que eu pensava."

Não demorou muito para Pagu perceber que o novo relacionamento não representava a liber- dade, e sim a reprodução daquilo que ela estava fugindo, o ambiente autoritário opressor da casa de seus pais. "Pensei: 'Mas meu pai não deu essa oportunidade, mas eu pensei que você iria me dar'. Não era do jeito que eu pensava."

A condição de gravidez não protegeu as mulheres, que continuavam sendo agredidas de todas as formas, inclusive física. "Ele me deu duas pancadas quando estava grávida, uma vez ele me jogou dentro do fusca e a outra ele me deu um murro na cara, foi a gota d'água" (Bárbara).

A gravidade da situação levou Bárbara a se decidir pela separação, mas o companheiro não aceitou e continuou perseguindo-a por todos os lugares e os dois acabaram reatando: "Mas daí ele ficava correndo atrás, ele me cercava na rua Amando, ele cercava, onde eu estava ele estava atrás."

Para Leonilda, a gravidez foi a época de maior vulnerabilidade em relação à violência física, a tal ponto que temia que o filho nascesse com sequelas. "Grávida foi a época que eu mais apanhei, graças a Deus meu filho nasceu perfeito, eu apanhei muito na barriga, estava de nove meses ele me tacou uma pedra enorme na cabeça, quase morri."

Contudo, dar um ponto final em um relacionamento abusivo é mais difícil e complexo do que sair da casa dos pais para formar uma família, "e ele ficou completamente pirado. Eu nem sei se você achou na delegacia o motivo que eu fui lá” (Leolinda).

No caso de Chiquinha Gonzaga, o companheiro já demonstrava traços de violência, poder e possessividade antes da união. "Ele sempre foi assim, ciumento, possessivo.” Entretanto, foi após o casamento que a situação se tornou insustentável: "Mas nada como ele se tornou depois, as pessoas mudam e ele mudou para pior."

E quando o casamento não dava certo, o jeito era retornar para casa e continuar sofrendo agressões cotidianamente, conforme narrativa de Nísia Floresta: "Então eu consegui escapar logo por que eu saí de casa com 11 anos, depois eu voltei com 13, daí continuei apanhando, aí quando eu casei, separei e continuei apanhando, aos 40 anos continuei apanhando do meu pai.”

\section{Discussão}

As mulheres deste estudo vivenciaram, desde a infância, a divisão sexual do trabalho. Ao ajudar a mãe assumindo atribuições relacionadas aos cuidados com a casa e com os demais membros da 
família, essas mulheres foram sendo socializadas para o papel destinado historicamente à mulher ${ }^{16}$. Não que as mães tenham sido algozes das próprias filhas, mas reproduziram o que lhes foi incutido pelo paradigma estrutural do poder masculino, introjetado pelos sujeitos na sociedade, tornando-se difícil enxergá-lo como não "natural"².

Dessa forma, quando o pai e/ou a mãe delegam às meninas a responsabilidade sobre os afazeres domésticos e o cuidado com os irmãos, estão introduzindo subjetivamente a ideologia patriarcal na infância e construindo os valores das desigualdades de gênero como verdades absolutas $^{24}$.

Essa divisão sexual do trabalho tende a legitimar a dominação e o poder masculino como algo natural e inquestionável, transferindo o modelo de geração para geração, tornando um grande desafio romper com esse padrão ${ }^{25}$. O poder e o controle aos quais as mulheres são submetidas desde crianças propiciam, ainda na infância, situações de violência e opressão que poderão ser estendidas aos futuros relacionamentos ${ }^{23,25}$.

No entanto, é importante ressaltar o amplo sentido da "divisão sexual do trabalho", para além da descrição concreta do que diz respeito a cada sexo biológico, e portanto à desigualdade sexual. É a busca constante da articulação do real com uma reflexão crítica sobre os processos utilizados pela sociedade para hierarquizar os papéis sociais de gênero. Observa-se, então, que a relação entre gêneros, assim definida, é antagônica e, sendo construções sociais, não advém de uma causalidade biológica ${ }^{26-28 .}$

Dada a inexistência da perspectiva de gênero na teoria marxista das classes sociais, o feminismo materialista incorporou ao debate a divisão sexual do trabalho profissional e do trabalho doméstico como categorias do poder e do saber implícitas nas relações sociais de sexo, partindo do pressuposto de que a teoria marxista não permitia a apreensão do lugar das mulheres na produção e reprodução social ${ }^{27,28}$.

Para Gayle Rubin, a divisão sexual do trabalho é um dispositivo que visa estabelecer um estado recíproco de dependência mútua entre os sexos, que os obriga a formar uma família. Os sistemas de parentescos, segundo ela, não são biológicos, e sim de categorias e de estatutos, ou seja, a imposição de uma organização cultural em detrimento de uma procriação biológica; tal teoria se ancora na ideia de Lévi-Strauss sobre as Estruturas elementares do parentesco (1949) ${ }^{29}$.

Nessa linha de raciocínio, para que o sistema funcione bem, as mulheres não devem ter plenos direitos sobre si e sua sexualidade deve corresponder aos desejos dos outros, não aos seus próprios. Desse modo, Gayle Rubin defende a ideia de que os sexos se organizam socialmente com base no gênero, na heterossexualidade compulsória e na opressão feminina ${ }^{30,31}$.

A educação sexista por intermédio das quais essas mulheres foram socializadas foi apreendida sob o alicerce das qualidades, habilidades e funções, diferenciando-se conforme o sexo biológico. Vale lembrar que a educação sexista aqui abordada se refere não só àquela que distingue homens de mulheres, mas àquela que a naturaliza e define como determinante biológico, reafirmando a tese de Gayle Rubin de que o sistema sexo/genêro como dispositivo de organização transforma a sexualidade biológica das mulheres em produto de atividade humana ${ }^{30,31}$.

Neste estudo chamou atenção o caráter intergeracional que perpassou essas experiências, reproduzindo, no decorrer dos tempos e das trajetórias de vida, estereótipos de uma cultura patriarcal que pode perpassar gerações caso não haja questionamento, problematização e resistência ${ }^{24}$.

O conceito de mulher, sob a perspectiva de Simone de Beauvoir, é de construção social, e não "natural", com base no sexo biológico, processo esse que vem contribuindo para a desconstrução da naturalização dos sexos e, portanto, para destituir hierarquias ${ }^{32}$. Observou-se no presente estudo que esse modelo que subordina, domina e inferioriza as mulheres por causa do sexo biológico foi ganhando espaço na vida dessas mulheres ainda na adolescência, quando os pais as reprimiam por terem atividades fora de casa e contato com meninos.

Os pais, chefes da família, mantêm as rédeas de todos os membros, nunca são contrariados ou desobedecidos, e assim os mantém sob controle, seja por intimidação, manipulação emocional ou violência física. As filhas já estão sendo preparadas para obedecer e não contrariar o futuro marido $^{23}$ Sob a ótica sociocultural e histórica, essa dinâmica acaba se refletindo e se reproduzindo por meio da violência conjugal.

Segundo a literatura, as principais motivações para a prática de violência contra a mulher no relacionamento conjugal são: a desobediência ao marido, a não preparação da comida, a falta de cuidado com os filhos e afazeres domésticos e a recusa em ter relações sexuais ${ }^{32,33}$.

Como mencionado, a busca dessas mulheres por autonomia e liberdade contribuiu para a tomada de decisões precipitadas, ao saírem de 
casa para morar com o namorado, e também dificultou a decisão de sair da situação de violência conjugal. O conceito de autonomia compreende cinco dimensões: 1) a primeira se relaciona à liberdade na tomada de decisões relativa aos filhos e a situações econômicas; 2) mobilidade, ausência de ameaça do companheiro, e está relacionada a situações de violência pelo parceiro íntimo; 3) engloba o acesso a recursos sociais e econômicos; 4) controle sobre recursos econômicos; e 5) regulação da fertilidade e maternidade segura, essa dimensão se aplica especialmente às mulheres jovens ${ }^{34,35}$.

A autonomia das mulheres é um processo que deve começar na infância, na família, com uma socialização que problematize as desigualdades de gênero presente no atual contexto; assim, as meninas podem crescer em um ambiente sociocultural que propicia a compreensão crítica dos papéis de gênero na sociedade. Tal processo não foi construído na dinâmica familiar dessas mulheres, pelo contrário, a socialização foi uma reprodução da ordem societária patriarcal, com nítida presença do machismo nas diferentes formas de violência vividas por elas desde a infân$\mathrm{cia}^{36}$.

Estudos evidenciaram que as mulheres que possuem controle sobre a própria vida, com acesso a recursos sociais e materiais - como renda, emprego, habitação, alimentação, reconhecimento e conhecimento no âmbito familiar, comunitário e societário -, têm condição de escolher e alterar suas trajetórias de vida ${ }^{34-36}$. No caso das mulheres deste estudo, a autonomia foi comprometida desde a infância pela desproteção familiar frente a diferenças de gênero e à socialização com foco na dominação masculina $a^{34-36}$.

Sob a ótica da socialização de gênero, esta pesquisa partiu da premissa de que a ordem patriarcal é um modelo que estrutura a realidade social brasileira. Ambos os sexos estão sob esse padrão de normas que influencia a violência contra a mulher, dado o caráter cultural e histórico que determina comportamentos, gostos, hábitos e atitudes que homens e mulheres devem ter e seguir.

Dessa forma, a desigualdade de gênero influenciou transgeracionalmente tanto o comportamento das participantes da pesquisa quanto o de seus respectivos pais, ou seja, assim como as filhas foram socializadas para a submissão, os pais foram socializados para a dominação. É preciso compreender o patriarcado como uma relação dinâmica e transgeracional que socializa ambos os gêneros. Portanto, o modelo de pai que reproduz cultural e fielmente tais normas e regras também foi incutido em suas próprias trajetórias de vida ${ }^{32}$.

Quando as mulheres tomam a decisão de fugir das amarras paternas, estando ainda com baixo nível de escolaridade, sem nenhuma qualificação profissional e maturidade para entrar em um relacionamento, tornam-se vulneráveis, dependentes e predispostas a sofrerem violência, pois ainda não desenvolveram capacidade para decifrar os perigos de uma união precoce, muito menos para agir em circunstâncias de violência por parte do parceiro íntimo. Nesse sentido, as uniões precoces se tornam uma estratégia malsucedida de busca pela liberdade, comprometida pela forma como foram socializadas no ambiente familiar ${ }^{37}$.

Ao longo da história, a mulher foi educada para se casar e ter filhos. Só lhes era possível duas escolhas na vida: seguir o celibato e a religião ou se casar com o consentimento do pai. Porém, o casamento significava um contrato inquebrável, para a vida toda, não sendo permitida a separação para as mulheres. No Brasil, sob o amparo do movimento feminista, em 1977 foi promulgada a Lei 6.515, denominada Lei do Divórcio, que permitiu às mulheres escolherem continuar ou não no relacionamento ${ }^{38,39}$. Contudo, embora essa lei existir há mais de 30 anos, resquícios dessa forma de pensar e ver a mulher na sociedade ainda engendram formas de controle, preconceito e submissão. No contexto atual, será que os novos relacionamentos podem ter substituído o modelo de controle físíco por um modelo de controle mental/cultural? $\mathrm{O}$ contexto atual não seria uma releitura do patriarcado?

Estudos realizados em relação à gravidez na adolescência encontraram associação entre gravidez antes dos 19 anos e relacionamentos nos quais o parceiro tentou exercer algum tipo de violência física e controle sobre elas. A dinâmica sociofamiliar dessas adolescentes acaba influenciando a tomada de decisões precipitadas, como a de ir morar com o namorado, em um momento que deveria ser destinado à escolarização, à qualificação profissional e ao lazer com os amigos ${ }^{38,40}$.

Quando as filhas saem da casa do pai casadas, significa que eles cumpriram seu papel. Mas separar-se do marido significa rejeitar todo um modelo de controle e opressão e assim contrariar a percepção de mundo desses homens e do que eles esperam de uma mulher: submissão e domínio $^{30}$. 


\section{Considerações finais}

As mulheres do presente estudo foram socializadas conforme o modelo patriarcal, em um contexto familiar machista e opressor. Percebeu-se que o controle dos pais sobre a sexualidade das filhas estava focado apenas no medo da reprodução sexual, e não na formação profissional para produção social, inserção no mercado de trabalho, autonomia e independência financeira. Tais comportamentos contribuem para a reprodução da opressão feminina no ambiente doméstico, acentuando a dificuldade de elas se inserirem e alterarem suas formas de inclusão na sociedade de classes.

Esta pesquisa traz, para o campo de saúde coletiva, uma nova perspectiva de abordagem da mulher em situação de violência, a partir de sua história de vida, seu contexto social e histórico, mas acima de tudo sob a ótica da sociedade de classes e da naturalização do papel feminino de reprodução sexual.

Além disso, este estudo aponta a importância de se problematizar a socialização de gênero com mulheres, mães e filhas adolescentes, visando romper com a naturalização da opressão feminina, com os serviços de atenção primária à saúde sendo um local propício para tal prática, justamente por serem espaços que devem promover a saúde e prevenir agravos à saúde.

É importante ressaltar que o caráter qualitativo e regional da pesquisa não permite generalizações, porém ela se demostrou pertinente, dada a possibilidade de se identificar as subjetividades e percepções de mundo das participantes em uma perspectiva das lembranças e memórias das relações familiares desde a infância. Entretanto, por ser um estudo regional, podem estar presentes questões socioculturais, com valores e formas de enfrentamento das relações de gênero que se dão de outras formas em outros contextos.

\section{Colaboradores}

DF Machado trabalhou na concepção do artigo, revisão bibliográfica, análise dos resultados e redação final do texto. ERL Castanheira e MAS Almeida colaboraram va revisão bibliográfica e na elaboração e revisão final do texto.

\section{Agradecimentos}

À professora Ana Flávia Pires Lucas d'Oliveira, do Departamento de Medicina Preventiva da Faculdade de Medicina da Universidade de São Paulo, pela leitura crítica e pelas valiosas sugestões.

\section{Referências}

1. Waiselfisz JJ. Mapa da violência 2015 - homicídio de mulheres no Brasil. Brasília: OPAS/OMS, ONU Mulheres, SPM, Flacso; 2015. [acessado 2019 Jul 28]. Disponível em: https://www.mapadaviolencia.org.br/ pdf2015/MapaViolencia_2015_mulheres.pdf

2. Saffioti HIB. Contribuições feministas para o estudo da violência de gênero. Cad Pagu 2001; 16:115-136.

3. Vianna C, Ridenti S. Relações de gênero e escola: das diferenças ao preconceito. In: Aquino JG, organizador. Diferenças e preconceito na escola: alternativas teóricas e práticas. São Paulo: Summus; 1998. p. 93-105.

4. Hanada H, D'Oliveira AFPL, Schraiber LB. Os psicólogos na rede de assistência a mulheres em situação de violência. Estud Fem 2010; 18(1):33-59.

5. Schraiber LB, D'Oliveira AFPL, Portella AP, Menicucci E. Violência de gênero no campo da saúde coletiva: conquistas e desafios. Cien Saude Colet 2009; 14(4):1019-1027.

6. Scott J. Gênero: uma categoria útil de análise. Educ Real 1995; 20(2):71-99.

7. Saffioti HIB. Rearticulando gênero e classe social. In: Costa AO, Bruschin IC, organizadores. Uma questão de gênero. Rio de Janeiro: Rosa dos Tempos; 1992. p. 183-215.

8. Saffioti HIB. Gênero, patriarcado, violência. São Paulo: Expressão Popular, Fundação Perseu Abramo; 2015. 
9. Lauretis ST. A tecnologia do gênero. In: Holanda HB, organizador. Tendências e impasses: o feminismo como crítica da cultura. Rio de Janeiro: Rocco; 1994. p. 123132.

10. Alves AES. Divisão sexual do trabalho: a separação da produção do espaço reprodutivo da família. Trab Educ Saude 2013; 11(2):271-289.

11. Schwantes C, Andrade V. Mulheres no campo da pesquisa em física e ciências exatas na contemporaneidade. In: Stevens C, Oliveira S, Zanello V, Silva E, Portela C, organizadores. Mulheres e violências: interseccionalidades. Brasília: Technopolitik; 2017. p. 445-457.

12. Portela CA. Gênero, etnicidade e suas interseccionalidades: narrativas Kura-Bakairi na Universidade de Brasília. In: Stevens C, Oliveira S, Zanello V, Silva E, Portela C, organizadores. Mulheres e violências: interseccionalidades. Brasília: Technopolitik; 2017. p. 423444.

13. Duque-Arrazola LS. O cotidiano sexuado de meninos e meninas em situação de pobreza. In: Madeira FR, organizador. Quem mandou nascer mulher? Rio de Janeiro: Record, Rosa dos Tempos; 1997. p. 343-402.

14. Lavinas L. Gênero, cidadania e adolescência. In: Madeira FR, organizador. Quem mandou nascer mulher? Rio de Janeiro: Record, Rosa dos Tempos; 1997. p. 1143.

15. Giffin KM. Nosso corpo nos pertence: a dialética do biológico e do social. Cad Saude Publica 1991; 7(2):190-200.

16. Hall S. A identidade cultural na pós-modernidade. Rio de Janeiro: DP\&A; 1999.

17. Souza FC. Desvendando práticas familiares e escolares a partir das relações de gênero: uma reflexão sobre a educação de meninos e meninas [tese]. Araraquara: Universidade Estadual Paulista, Faculdade de Ciências e Letras de Araraquara; 2007.

18. Minayo MCS. O desafio do conhecimento: pesquisa qualitativa em saúde. São Paulo: Hucitec; 2004.

19. Brasil. Presidência da República. Politica nacional de enfrentamento à violência contra as mulheres. Brasília: Secretaria de Políticas para as Mulheres; 2007.

20. Bardin L. Análise de conteúdo. Lisboa: Edições 70; 2009.

21. Gadoni-Costa LM, Zucatti APN, Dell'Aglio DD. Violência contra a mulher: levantamento dos casos atendidos no setor de psicologia de uma delegacia para a mulher. Psicol Estud 2011; 28(2):219-227.

22. Rabello $\mathrm{P}$, Caldas Júnior A. Violência contra a mulher, coesão familiar e drogas. Rev Saude Publica 2007; 41(6):970-978

23. Bandeira LM. Violência de gênero: a construção de um campo teórico e de investigação. Soc Estado 2014; 29(2):449-469.

24. Nascimento ACO. Divisão sexual dos brinquedos infantis: uma reprodução da ideologia patriarcal. Soc Quest 2014; 17(32):257-276.

25. Corradi C. Violence, identité et pouvoir: pour une sociologie de la violence dans le contexte de la modernité. Socio-logos 2009; 4:1-11.

26. Dutra D, Bandeira L. Estudos de gênero na América Latina: dinâmicas epistêmicas e emancipações plurais. Rev Estud Pesqui Am 2015; 9(2):1-15.
27. Kergoat D. La division du travail entre les sexes. In: Kergoat J, Jacot $\mathrm{H}$, Boutet J. Le monde du travail. Paris: La Découverte; 1998. p.319-329.

28. Kergoat D. Divisão sexual do trabalho e relações sociais de sexo. In: Hirata H, Laborie F, Le Doaré $\mathrm{H}$, Senotier D, organizadores. Dicionário crítico do feminismo. São Paulo: Editora UNESP; 2009, p. 67-75.

29. Lévi-Strauss C. Les structures élémentaires de la parenté. Paris: PUF; 1949.

30. Cisne e Brettas T. Que homens e mulheres educamos? In: Tavares JMC, Marinho Z, organizador. Educação, saberes e práticas no oeste potiguar. Fortaleza: UFC; 2009. p. 61-77.

31. Rubin G. The traffic in women: notes on the "Political Economy" of sex. In: Reiter RR, editor. Toward an anthropology of women. New York, London: Monthly Review Press; 1975. p. 157-210.

32. Navarro-Swain T. O patriarcado rides again. In: Stevens $\mathrm{C}$, Oliveira S, Zanello V, Silva E, Portela C, organizadores. Mulheres e violências: interseccionalidades. Brasília: Technopolitik; 2017. p. 50-64.

33. Organização Mundial de Saúde (OMS). Global Status Report on Violence Prevention 2014. Genebra: OMS; 2014.

34. Koller SH, organizador. Adolescência e psicologia: práticas e reflexões críticas. Rio de Janeiro: Conselho Federal de Psicologia; 2002.

35. Sen G, Batliwala S. Empowering women for reproductive rights. In: Presser HB, Sen G, organizador. Women's empowerment and demographic processes. Oxford: Oxford University Press; 2000.

36. Casique I. Trabajo femenino extradoméstico y riesgo de disolución de la primera unión e el caso de las mujeres urbanas en la región capital de Venezuela. Papeles Poblac 2000; 6(25):35-57.

37. Levy MSF. A escolha do cônjuge. Rev Bras Estud Popul 2009; 26(1):117-133.

38. Waissman AL. Análise dos fatores associados à recorrência da gravidez na adolescência [tese]. São Paulo: Faculdade de Medicina da Universidade de São Paulo; 2006.

39. Pereira ISA, Silva JC. Escolha conjugal feminina: uma análise intergeracional segundo uma perspectiva crítica em psicologia. Psicol Estud 2013; 18(3):407-417.

40. Colombo MA. O princípio constitucional da igualdade e a condição jurídica da mulher na legislação civil brasileira com enfoque no direito de família [monografia]. Florianópolis: Universidade Federal de Santa Catarina; 2008.

Artigo apresentado em 29/12/2018

Aprovado em 20/04/2020

Versão final apresentada em 22/04/2020

Editores-chefes: Romeu Gomes, Antônio Augusto Moura da Silva 